\title{
Experimentando a desumanização: Paulo Freire e o uso didático de animais
}

Thales de Astrogildo e Tréz

\begin{abstract}
Resumo
A prática com animais na educação vem sendo cada vez mais problematizada, à luz das mais distintas abordagens. Esta prática é frequente na didática encontrada nos mais diversos cursos das áreas de ciências biológicas e da saúde. As análises críticas destas práticas didáticas vêm se utilizando de linhas voltadas eminentemente à didática no ensino superior e à ética. $O$ presente artigo aborda a temática a partir de uma perspectiva inédita: à luz do pensamento e obra do educador Paulo Freire. Nele, o processo de desumanização embutido em tais práticas didáticas, sua configuração enquanto situação limite, contextualização enquanto realidade opressora, e as potenciais possibilidades de humanização são exploradas afim de compreende-las sob uma ótica emancipadora. Articulam-se também conceitos de dialogicidade e problematização às situações de alto potencial de conflito moral. Por fim, uma adaptação de categorias encontradas em Giroux é apresentada para aplicação aos estudantes, fundamentada nas idéias apresentadas.
\end{abstract}

Palavras-chave: Paulo Freire, uso de animais, humanização, Henry Giroux, educação científica superior

\section{Abstract}

Experiencing dehumanization: Paulo Freire and didactic use of animals

The practice with animals in education has been increasingly criticized, through many approaches. This practice is widespread in the didactics found in a wide range of courses related to health and biological sciences. The criticism on this practice has been driven by didactics in higher education and ethics. This article intends to approach the theme from the perspective of the Brazilian educator Paulo Freire. In this sense, the process of dehumanization built-in in such procedures, its configuration as a boundary situation and contextualization while oppressive reality, and the possibilities of humanization that can derive from them are explored, aiming to understand these practices under an emancipatory perspective. Still, articulate the concepts of dialogicity and problematization to the practices considered as with high moral conflict potential. Finally, an adaptation on the intellectual teachers categories found in Giroux is applied to students, based on the ideas presented.. 
Keywords: Paulo Freire, animal use, humanization, Henry Giroux, higher science education

\section{Introdução}

A utilização de animais como instrumentos didáticos ${ }^{1}$, bastante comum na educação científica de nível superior, vem sendo cada vez mais problematizada no cenário brasileiro, à luz das mais distintas abordagens. A utilização de modelos animais como recurso em aulas práticas é parte frequentemente integrante da didática encontrada nos mais diversos cursos das áreas de ciências biológicas e da saúde, e tem a finalidade de demonstrar aspectos biológicos de diferentes naturezas (metabólicos, anatômicos, fisiológicos, farmacológicos, comportamental, etc.) e desenvolver procedimentos e habilidades específicos (técnicas de incisão e sutura, manobras cirúrgicas, manuseio animal, etc.). Até então, as análises críticas destas práticas didáticas vem se utilizando de linhas voltadas eminentemente à didática no ensino superior e à ética.

O presente artigo aborda a temática a partir de uma perspectiva inédita: à luz do pensamento e obra do educador Paulo Freire. Nele, o processo de desumanização embutido em tais procedimentos didáticos, sua configuração enquanto situação limite, contextualização enquanto realidade opressora, e as possibilidades de humanização que surgem a partir dele serão exploradas afim de compreender esta prática sob uma ótica emancipadora. Ainda, articular os conceitos de dialogicidade e problematização às situações consideradas como de alto potencial de conflito moral. Por fim, uma adaptação das categorias de professores intelectuais de Giroux (1997) será apresentada de forma a aplicar e adaptar estas aos estudantes, a partir de uma leitura transversal baseada em Paulo Freire.

\section{As transposições em Paulo Freire}

É sabido que a contribuição inicial de Paulo Freire se deu a partir de trabalhos com alfabetização de adultos, em situações não-formais de ensino, mas não se limitou a ela - a partir da segunda metade dos anos 80 seu pensamento percorre outros caminhos que avançam em outras leituras e possibilidades (Scocuglia, 1999b; Mejía, 1999). Sua abordagem francamente ideológica (e ideologizante) do processo educativo é marcante ao longo de suas muitas obras, para onde também destina instrumentos de síntese e análise que se ocupam não apenas da

\footnotetext{
${ }^{1}$ As práticas com animais em referência neste artigo são aquelas onde os animais, vertebrados ou não, saudáveis ou não, são mortos antes, durante ou após os experimentos, para fins exclusivamente didáticos. É possível pensar no uso ético de animais, onde não há nenhum tipo de prejuízo para os mesmos (como por exemplo em estudos de observação, ou no ensino de técnica cirúrgica com cadáveres animais obtidos eticamente).
}

R. B. E. C. T., vol 4, núm 2, mai./ago. $2011 \quad$ ISSN - 1982-873X 
denúncia ao processo de desumanização do ser humano enquanto ser submetido a condições diversas de opressão, como também de afirmar este mesmo ser humano como agente de transformação da realidade, inserindo-o num contexto de diálogo que visa emancipá-lo das adversidades que limitam sua existência em comunhão com o mundo.

Sua perspectiva libertadora provoca importantes reflexões sobre os processos educativos que acontecem no âmbito formal, principalmente no conceito de educação bancária. Neste sentido, muitos autores vêm se apropriando do pensamento de Paulo Freire e transpondo muitos de seus conceitos para o campo da educação escolar, reconhecendo em seu conceito de educação "o importante papel de elevar o nível de consciência dos educandos a respeito de suas condições de vida" (Delizoicov, 2008). Mesmo havendo o reconhecimento de que esta transposição não é imediata e requer investigação (ibid.), quando em curso, ela vem possibilitando uma abordagem crítico-transformadora da realidade escolar, de seus agentes, contexto social e currículos, fundamentada em uma clara opção político-ideológica. Segundo Scocuglia ${ }^{1}$,

\begin{abstract}
"Entendemos que se suas propostas político-pedagógicas não permitissem novas descobertas e novas experimentações, como partes intrínsecas da sua própria concretude, existência e disseminação, tornar-se-iam inertes $e$ enrijecidas. Suas propostas foram feitas para serem recriadas, conforme $o$ cotidiano, o imaginário, os interesses e os valores, conforme as condições de vida de seus praticantes - educandos e educadores"
\end{abstract}

Neste sentido, a educação científica no nível básico também tem se aproveitado da contribuição deste educador, de onde projetos diversos vêm objetivando "enfrentar problemas de investigação oriundos da transposição da concepção de educação de Paulo Freire ao ensino formal de ciências nas escolas", articulando alguns de seus conceitos na formação de docentes em ciências naturais, elaboração de programas escolares, produção de materiais didáticos e proposta de práticas docentes (Delizoicov, 2008). No entanto, esta mesma transposição para a educação científica superior, no sentido de compreender os processos educativos que ali se desenrolam, parece ser bastante tímida, ainda que alguns trabalhos possam ser encontrados na área da saúde (Rozendo et al., 1999; Cyrino e Toralles-Pereira, 2004).

\footnotetext{
${ }^{1}$ Scocuglia, A.C. A história das idéias de Paulo Freire e a atual crise de paradigmas. 2a edição. João Pessoa: Ed. Universitária UFPB, 1999a. p.23.
} 


\section{Quando Eva vê a uva.}

"Eva viu a uva". A frase utilizada por Paulo Freire como parte de sua crítica ao método de alfabetização de adultos, virou um emblema de um processo bancário que poderá nos dizer muito sobre as práticas com animais. Tomada como processo, a frase denuncia não apenas sua dimensão pré-fabricada e abstrata. Mais além, Paulo Freire chama atenção para os elementos que o constituem: quem é Eva? Qual seu contexto social? Quem produz a uva? Quem se beneficia com este trabalho? Tratar este processo sem estas considerações e problematizações é marca da concepção bancária, cujo ato educativo consiste essencialmente da narração de conteúdos, por parte do educador, que tendem a petrificar-se. Sua concepção implica em conceder aos educandos a única ação possível: a de receberem os depósitos do educador, guarda-los e arquivalos. O educador é aquele que sabe, pensa, diz a palavra, disciplina, opta e prescreve sua opção, atua, escolhe o conteúdo... é o sujeito do processo e a negação do educando. Implica também em anular "o poder criador dos educandos ou o minimiza, estimulando sua ingenuidade e não sua criticidade" (Freire, 2005). Inaugura-se aí o anti-diálogo. A permanência da realidade, e não sua transformação, se dá na contramão do diálogo, e no sentido do anti-diálogo, que nega o jogo contraditório da permanência e da mudança.

Não são poucas as iniciativas pedagógicas que falham quando o educador parte de uma visão estritamente pessoal da realidade, ao não considerar "os homens em situação a quem se dirigia seu programa, a não ser como puras incidências de sua ação" (ibid). O educador bancário reage, até mesmo instintivamente, "contra qualquer tentativa de uma educação estimulante do pensar autêntico", mas, segundo Freire ${ }^{1}$, não parece perceber que

"nos próprios 'depósitos' se encontram as contradições, apenas revestidas por uma exterioridade que as oculta. E que, cedo ou tarde, os próprios 'depósitos' podem provocar um confronto com a realidade em devenir e despertar os educandos, até então passivos, contra a sua domesticação"

Apesar de imersos nesta realidade considerada como opressora, o posicionamento dos estudantes em relação aos procedimentos em questão sugere um nível de consciência crítico que se volta, se não para a análise, pelo menos para a percepção destas práticas enquanto problemáticas. Existe aí, no mínimo, um germe que se indaga da viabilidade de sua humanização, que segundo Freire ${ }^{2}$ assume hoje um caráter de preocupação iniludível:

"Os movimentos de rebelião, sobretudo dos jovens, no mundo atual, que necessariamente revelam peculiaridades dos espaços onde se dão, manifestam, em sua profundidade, esta preocupação em torno do homem e

\footnotetext{
${ }^{1}$ Freire, P. Pedagogia do oprimido. 47ạ edição. Rio de Janeiro: Paz e Terra, 2005. p.70.

${ }^{2}$ Ibid, p.31.

R. B. E. C. T., vol 4, núm 2, mai./ago. $2011 \quad$ ISSN - 1982-873X
} 
dos homens, como seres no mundo e com o mundo. Em torno do que e de como estão sendo. (...) ao exigirem a transformação das universidades, de que resultem, de um lado, o desaparecimento da rigidez nas relações professoraluno; de outro, a inserção delas na realidade; (...) ao rechaçarem velhas ordens e instituições estabelecidas, buscando a afirmação dos homens como sujeitos de decisão"

No entanto, o silêncio exercido - imobilismo enquanto ação - por parte destes, parece indicar que o opressor não está sendo localizado concretamente. Esta condição, junto com a de não chegar à "consciência para si", conduz o estudante à posição do fatalismo. O respeito à autoridade mitificada do professor/cientista, no contexto da educação científica superior, é emblemática numa passagem onde o camponês, em face de um tema que lhe é problemático, diz ao educador: "desculpe, nós devíamos estar calados e o senhor falando. O senhor é o que sabe; nós, os que não sabemos" (ibid). Freire caracteriza a autodesvalia como marca do oprimido.

Pelo que vimos até então, pode-se dizer que um dos elementos que motiva e permeia a produção de Paulo Freire é o que se entende por opressão. A condição de realidade na opressão é fundamentada no domínio do outro, na sua negação enquanto sujeito. Assim, "a realidade opressora, ao constituir-se como um quase-mecanismo de absorção dos que nela se encontram, funciona como uma força de imersão das consciências" (ibid).

A condição de opressão implica na existência das categorias opressor-oprimido. Esta dicotomia é apenas aparente, já que se compreende uma relação não apenas dialética como também, segundo Freire, contraditória. Existe, de fato, a condição de opressor enquanto categoria beneficiada da "posse direta, concreta e material do mundo", cujo lucro é o seu objetivo principal, e do oprimido enquanto excluído material, econômica e politicamente. Mas para além desta condição "de classe", há ainda a condição existencial destas categorias, que segundo Mendonça ${ }^{1}$,
"envolve a dimensão relacional da consciência-mundo do opressor, que se caracteriza enquanto ser-no-mundo pelo sentido do ter, e do oprimido, enquanto consciência fragmentada e alienada do sentido do ser"

Na presente análise, o conceito de opressor e oprimido é utilizado como referência, respectivamente, ao professor afinado à concepção bancária de educação (ser-detentor do conhecimento), e ao estudante condicionado pelas (e adaptado às) condições instauradas por esta concepção/realidade. A situação objetiva de opressão, neste cenário, é sugerida nos dados

\footnotetext{
${ }^{1}$ Mendonça, N.J.A. A humanização na pedagogia de Paulo Freire. Dissertação. UFPE. 2006. p. 45.
} 
que se mostram no quadro 1 , além de narrativas que configuram esta situação pedagógica enquanto desumanizadora, como veremos mais adiante.

\section{Eva e a uva.}

Uma série de pesquisas recentes pode ajudar a visualizar algumas dimensões da situação de (potencial) conflito e (efetivo) silêncio referente à temática das práticas com animais. $\mathrm{O}$ quadro abaixo é baseado em pesquisas com estudantes e professores do ensino superior, majoritariamente de cursos das áreas da saúde e biológicas:

Quadro 1 - Dados obtidos em pesquisas sobre a percepção discente da experimentação animal para finalidades didáticas.

\begin{tabular}{|l|c|c|l|c|}
\hline \multicolumn{1}{|c|}{ Dado } & $\begin{array}{l}\text { Acha } \\
\text { questionável } \\
\text { / importante } \\
\text { debater }\end{array}$ & $\begin{array}{l}\text { Reconhece } \\
\text { problemas } \\
\text { éticos }\end{array}$ & $\begin{array}{l}\text { Prática } \\
\text { “desagradável } \\
\text { " ou } \\
\text { "incômoda” }\end{array}$ & $\begin{array}{l}\text { Professores não } \\
\text { indagam sobre } \\
\text { possíveis } \\
\text { objeções }\end{array}$ \\
\hline Trez (2000) & - & $63,1 \%$ & $40,9 \%$ & $74,6 \%$ \\
\hline Shiue et al. (2004) & $69,5 \%$ & - & - & - \\
\hline $\begin{array}{l}\text { Mirault-Pinto \& } \\
\text { Rímoli (2005) }\end{array}$ & - & $45,9 \%$ & - & $83,3 \%$ \\
\hline Barbudo (2006) & - & $67,9 \%$ & $45,7 \%$ & $91 \%$ \\
\hline Sousa (2007) & - & - & - & - \\
\hline Lima (2008) Nakada & $83 \%$ & $85 \%$ & - & $80 \%$ \\
\hline $\begin{array}{l}\text { Tréz \& } \\
\text { (2008) }\end{array}$ & & & & \\
\hline
\end{tabular}

Podemos fazer algumas considerações sobre o que se coloca no quadro. Fica evidenciado na maioria das pesquisas que o procedimento didático com animais possui grande potencial de conflito. O reconhecimento de questões de natureza ética em tais práticas, que parece fundamentar este potencial de conflito, é, de fato, legítimo, uma vez que é crescente o apelo ambiental que emerge atualmente da sociedade, intimamente atrelado à forma como nos relacionamos com os animais em diversos âmbitos (Brugger, 2004). Soma-se a isto a produção acadêmica disponível que, nos últimos anos vem introduzindo na academia o tema socialmente emergente da exploração de animais - ainda que historicamente persistente, uma vez que a crítica à relação de exploração dos animais pelos seres humanos não é recente, e ocupou o pensamento de muitos pensadores clássicos, como Voltaire, Primatt, Bentham e outros. Este reconhecimento é visivelmente majoritário entre estudantes. A identificação do desagrado 
perante tais procedimentos também é considerável nas pesquisas: testemunhar a morte (por vezes agonizante) de animais para acessar conhecimentos já instituídos cientificamente pode ser uma experiência marcada por sensações negativas. Tréz \& Nakada (2008) identificaram em sua pesquisa o predomínio destas sensações entre estudantes (como angústia, culpa, incômodo, revolta e tristeza). Diversos estudos vêm tratando das implicações psicológicas destes procedimentos didáticos, que apontam para um processo de dessensibilização. Segundo a psicóloga norte americana Theo Capaldo ${ }^{1}$,

"estudantes podem sofrer trauma psicológico como resultado de se sentirem forçados a participar, ou em ver seus colegas participando, de comportamentos que julgam eticamente questionáveis"

Soma-se a isto, o "silêncio" derivado da falta de debate sobre tais procedimentos. Como visto em algumas das pesquisas acima, não há o costume, por parte dos professores, de indagar sobre possíveis objeções ao uso de animais junto aos estudantes. Em outras palavras: a maioria dos professores parece não valorizar esta dimensão subjetiva, o que contribui, neste caso, para a naturalização destas práticas, que passam a ser tomadas por certas. Sousa (2007) encontrou que uma pequena minoria (7\%) afirmou já haver se manifestado contra tais práticas. Dos que nunca haviam se recusado a praticar estes procedimentos, $40 \%$ alega que o fazem porque respeitam a metodologia do professor.

\section{Uma uva passada.}

As práticas com animais ainda podem ser consideradas, neste artigo, como o que Paulo Freire chama de contradição da contemporaneidade do não-coetâneo. Sabemos que nossa sociedade atual vive seus temas próprios e diversificados e que interagem com o todo em que participam. Considerando esta trama, Paulo Freire enfatiza ainda a dimensão epocal na qual os temas e visões de mundo estão embebidos. Ao possuírem uma trajetória histórica, estes se radicalizam, persistindo ou emergindo, preservando-se.

Se considerarmos como marco histórico a publicação da obra Exercício anatômico sobre o movimento do coração e sangue nos animais, do médico inglês William Harvey, em 1628 (que se utilizou de mais de 80 espécies de animais para sua sistematização, e foi o primeiro a empregar uma linguagem mais técnica e menos religiosa em sua obra), em uma investida que preparou o campo da abordagem científica da época, podemos afirmar que a prática da do uso de animais

${ }^{1}$ Capaldo, T. The Psychological Effects on Students of Using Animals in Ways that They See as Ethically, Morally or Religiously Wrong. ATLA, 32(1), 2004. p. 525 (grifo adicionado) 
tem pelo menos quatro séculos de história. À parte de qualquer descrição que remonte ao contexto de seu estabelecimento no século XVII, o que se observa atualmente é a persistência desta consciência didático-científica atrelada à emergência de outra consciência (não menos didático-científica) que a contradiz. Pode-se dizer que a concepção persistente assume alguns pressupostos: o animal enquanto objeto (reificação); um senso de justiça estreito e limitado aos membros de sua própria espécie (especismo); uma visão reducionista e mecânica do organismo; um conceito positivista do fazer científico e da própria ciência; etc.. Na concepção emergente encontramos sua antítese: o animal enquanto sujeito (ou no mínimo paciente moral); um senso de justiça ampliado que inclui outras espécies em suas considerações morais; uma visão complexa e orgânica do organismo; um conceito sócio-histórico do fazer científico e da própria ciência; etc. O hegemônico e o contra-hegemônico, então, convivem num mesmo espaço-tempo, numa relação rica em contradições.

O conhecimento é embebido de temporalidade, situando as diversas concepções em momentos sócio-históricos definidos. Nesta relação concepção-tempo, problematizar o campo hegemônico, que está associado ao poder e ao domínio do que-fazer didático-científico, é aqui considerada como uma tarefa humanizante. Assim, no caso das práticas com animais, se faz necessário discutir, além da sua dimensão histórica, o significado de seu achado, sua instrumentalidade. Os procedimentos didáticos com animais seriam, segundo Freire ${ }^{1}$, tema de diálogo, tendo em mente que

"o que se pretende com o diálogo não é que o educando reconstitua todos os passos dados até hoje na elaboração do saber científico e técnico. Não é que o educando faça adivinhações ou que se entretenha num jogo puramente intelectualista de palavras vazias. O que se pretende com o diálogo, em qualquer hipótese (seja em torno de um conhecimento científico e técnico, seja em torno de um conhecimento 'experimental'), é a problematização do próprio conhecimento em sua indiscutivel relação com a realidade concreta na qual se gera e sobre a qual incide, para melhor compreende-la, explica-la, transformala"

\section{Humanização: entre a Evanização e a Uvanização.}

A pedagogia transformadora busca a restauração do elemento intersubjetivo, de onde o diálogo é instrumento fundamental. No diálogo há a pronúncia da palavra, que, ao ser verdadeira, transforma o mundo: é práxis. Assim, não é no silêncio que o ser humano se faz.

${ }^{1}$ Freire, P. Extensão ou comunicação? 8a edição. Rio de Janeiro: Paz e Terra, 1983. p. 52

R. B. E. C. T., vol 4, núm 2, mai./ago. $2011 \quad$ ISSN - 1982-873X 
A necessidade de conscientização por parte dos educandos em relação aos diversos componentes de seu processo formativo também não se dá numa mera tomada de consciência, numa falsa apreensão da realidade, mas sim num teste de realidade, dentro da práxis, numa unidade dialética ação-reflexão. Segundo Freire ${ }^{1}$,

"Quanto mais conscientizados nos tornamos, mais capacitados estamos para ser anunciadores e denunciadores, graças ao compromisso de transformação que assumimos"

A tomada de consciência implica na compreensão das contradições, força-motora do processo educativo. É na contradição que surge o desafio, "fundamental à constituição do saber" (Freire, 1983). Por se fundamentar no desafio, o ato de conhecer exige uma postura impaciente, inquieta, indócil.

Segundo Freire (1979), ambos os temas da humanização e desumanização existem vinculados à ação humana, seja, respectivamente, transformando a realidade, seja preservando o status quo. Assim,

"A libertação não se dá dentro da consciência dos homens, isolada do mundo, se não na práxis dos homens dentro da história que, implicando na relação consciência-mundo, envolve a consciência crítica desta relação" ${ }^{2}$

As implicações pedagógicas do processo de humanização, além de levar a percepção da impossibilidade do que se entende por neutralidade da educação, denuncia os processos de transferência de conhecimento que nega o caráter ativo da consciência. Assim se processa a desumanização, que nega ao humano sua capacidade de reflexão, ação, criação e transformação da realidade.

Evanizar (subjetivismo) ou uvanizar (conteudismo) a educação representam movimentos de desumanização, neste sentido. Apesar da subjetividade ser considerada por Freire como importante no processo de transformação, uma vez compreendido seu papel como tarefa histórica e política (Giroux, 1997), o subjetivismo considerado como uma fuga da realidade objetiva uma vez que cria realidades "ensimesmadas", portanto, falsas. O conteudismo, por sua vez, é próprio da concepção bancária, como sintoma do "depósito", da narração, da alienação da ignorância. Ao coisificar o conteúdo, coisifica-se o estudante, o professor e o mundo.

${ }^{1}$ Freire, P. Conscientização: teoria e prática da libertação: uma introdução ao pensamento de Paulo Freire. 3a edição. São Paulo: Editora Moraes, 1980. p.28.

${ }^{2}$ Freire, P. Ação cultural para a liberdade e outros escritos. 4a edição. Rio de Janeiro: Paz e Terra, 1979. p. 98 
O conflito que se estabelece na prática com animais aqui se entende como visão de mundo: dele derivam valores que compõem a realidade moral no nível subjetivo, compondo o "universo temático" num nível maior. Mas o posicionamento do sujeito frente a esta realidade, numa perspectiva dialógica, deve vir acompanhado da problematização. Assim, Freire visa propor a situação existencial [do sujeito] como problema, que o desafia, exigindo-lhe resposta no campo da razão e da ação.

"frente a este 'universo' de temas que dialeticamente se contradizem, os homens tomam também suas posições contraditórias, realizando tarefas em favor, uns, da manutenção das estruturas, outros, da mudança" ${ }^{\prime 1}$

A investigação de percepções não apenas pode caracterizar o potencial de conflito que uma dada realidade pode provocar, como também identificar os "percebidos" em meio a este universo temático. O quadro apresentado acima parece sugerir que há de fato uma percepção que problematiza um aspecto da realidade, no entanto sem o destacar. Ou seja, não atinge o que Paulo Freire denomina de "percebido destacado":

"O que antes já existia como objetividade, mas não era percebido em suas implicações mais profundas e, às vezes, nem sequer era percebido, se 'destaca' e assume o caráter de problemas, portanto, de desafio"”2

A percepção por si só não basta, pois ela não implica em apropriar-se da realidade. 0 conceito de situação limite se torna fundamental aqui. Sua utilização por Paulo Freire é baseada em Álvaro Vieira Pinto (1909-1987), e aplica-se a situações que são compreendidas como marginais a uma nova realidade: uma fronteira entre o ser e o ser mais. A situação-limite, enquanto "percebido destacado", é um desafio a ser superado. Este movimento de superação é denominado ato-limite, aquele que se dirige à superação e à negação do dado, em lugar de implicar em sua aceitação dócil e passiva (Freire, 2005), e sua implicação leva ao inédito viável, uma nova condição de realidade que rompe com o fatalismo, e onde a contradição antes percebida e destacada deixa de existir para dar lugar a uma nova condição de interação. Do contrário, sua não transcendência leva o humano à adaptação.

A relação destes conceitos com o que observamos na temática que aqui se problematiza se dá no seguinte sentido: a visão de mundo de uma parcela de estudantes percebe as práticas didáticas com animais como contraditórias à sua realidade moral, muito embora ainda não se configure como uma situação-limite, uma vez que o status desta prática é ainda preservado pelo silêncio - sintoma da condição de adaptação. Pode-se sugerir que tais práticas sejam em muitos casos uma situação-limite em potencial, pois não é destacada enquanto desafio. Onde ela assim o

\footnotetext{
${ }^{1}$ Freire, P. Pedagogia do oprimido. 47ạ edição. Rio de Janeiro: Paz e Terra, 2005. p.107 ${ }^{2}$ Ibid, p.82

R. B. E. C. T., vol 4, núm 2, mai./ago. $2011 \quad$ ISSN - 1982-873X
} 
é, podemos perceber a diferença que o ato-limite gera em termos de superação da condição até então limitadora, como em alguns relatos. Tréz (2003) descreve a ação de um estudante de ciências biológicas que "roubou" um cão minutos antes de sua morte em um laboratório de fisiologia, cujo desdobramento levou a universidade a discutir esta utilização como nunca antes, e a substituir estas práticas com cães por outros recursos didáticos que não causavam a morte de outros animais. O caso do estudante Róber Bachinksi que, após perceber a postura irredutível da universidade onde cursava ciências biológicas, negando seu direito de objeção de consciência em não matar animais, moveu ação judicial e obteve algum sucesso (Vara Federal Ambiental, 2008). Em todos os casos, o ato-limite provoca reações que são características de uma realidade opressiva. É marcante neste sentido o testemunho encontrado em Mirault-Pinto ${ }^{1}$ enquanto estudante de veterinária que objetou às práticas didáticas letais em animais, de onde se tira que a resposta a tais manifestações costuma ser bastante reativa, a ponto de sofrer represálias, ridicularização, ameaças e, ainda, suspensão:

"Era difícil e complicado ir para a universidade. Era estranho estar em um lugar onde as opiniões eram divergentes. Aqueles que não tinham tido contato comigo, achavam que eu era louca. Outros não concordavam com nada do que eu dizia, mas respeitavam o meu direito de dizer. Muitos me apontavam nos corredores e comentavam o caso. Várias vezes fui coagida a abandonar o curso pelos próprios colegas. $O$ que ninguém entendia era que eu não estava brigando com professores, nem, muito menos, com alunos. Eu estava lutando pelo meu direito de aprender de uma forma que não ferisse meus princípios éticos e religiosos, que eu estava lutando contra um sistema que não se abria a novas formas de ensino por puro preconceito e tradicionalismo"

Em que pese que a transformação desta realidade didática seja condição de humanização daqueles que os denunciam e se vêem violentados por tal realidade, o ato-limite se justifica no sentido do ser mais.

\section{Categorias.}

Os dados encontrados nas pesquisas acima mencionadas provocam o pensar em categorias de estudantes, que podem servir de parâmetro não somente para os distintos processos, como

${ }^{1}$ Mirault-Pinto, M.C. Objeção consciente ao uso de animais: o conflito na sala de aula. In: Trez, T.A. (Org.) Instrumento animal: o uso prejudicial de animais no ensino superior. Bauru: Canal 6, 2008. p. 195 
para as distintas compreensões, embutidos na idéia de formação. Giroux (1992) parte do conceito Gramsciano de intelectual $^{1}$ para apresentar quatro categorias de educadores, como intelectuais: transformadores, críticos, adaptados e hegemônicos. Baseadas nestas, uma adaptação do que seriam estas categorias para os estudantes é apresentada abaixo:

Estudante intelectual transformador: engajado na articulação da dimensão pedagógica enquanto política, considerando o espaço acadêmico como dialético em suas relações entre grupos e indivíduos. Vê o processo de formação como espaço de reflexão crítica e ação, envolvido de forma consciente na luta contra injustiças e na transformação de si próprios. Igualmente engajado na articulação da dimensão política enquanto pedagógica, se percebendo como agente crítico, anunciador e denunciador, problematizando o conhecimento de forma a dar-lhe significado, e se utilizando do diálogo como instrumento de emancipação.

Estudante intelectual crítico: apesar de ideologicamente alternativo às instituições e formas de pensamento hegemônicos, não é engajado social e politicamente. "São incapazes de avançar de sua postura isolada para o terreno da solidariedade coletiva e da luta" (Giroux, 1992). Essa omissão é fundamentada muitas vezes em uma visão, se não fatalista, "muito complexa" da realidade - esta última no sentido escapista de evitar análises mais pontuais e "destacadas".

Estudante intelectual adaptado: assume uma posição ideológica e práticas materiais que sustentam e servem às instituições e formas de pensamento hegemônicos. Não é "agente do status quo", assumindo esta posição de forma geralmente inconsciente. Pode denunciar ou desdenhar a política: na primeira se recusa a correr riscos, na segunda se vangloria de (e sobrepõe) seu sistema de valores (muitas vezes em referência à "objetividade científica").

Estudante intelectual hegemônico: está a um passo da categoria anterior, ao conscientemente preservar a ordem existente e se subordinar moral e intelectualmente ao perfil das instituições e formas de pensamento hegemônicos.

Com o que foi apresentado de Paulo Freire até o momento, podemos articular as categorias de Giroux para compreender alguns dos posicionamentos em relação às práticas didáticas com animais:

Estudante intelectual transformador: identifica nas práticas com animais (percebidodestacado) uma situação-limite, e se engaja na sua transcendência. Sua motivação se dá fundamentada em uma noção de justiça ampla e compartilhada, e não como mero capricho individual. Não se limita a apenas descrever ou explicar o que identifica como problema. Pelo contrário, assume

\footnotetext{
${ }^{1}$ Assumindo que todas as pessoas são intelectuais ao pensar, fazer mediações e ao aderir a visões de mundo.
}

R. B. E. C. T., vol 4, núm 2, mai./ago. 2011

ISSN - 1982-873X 
"perante ele uma atitude comprometida. Atitude de quem não quer apenas descrever o que se passa como se passa, porque quer, sobretudo, transformar a realidade para que, o que agora se passa de tal forma, venha a passar-se de forma diferente" 1

Está conscientizado de seu papel enquanto sujeito na relação pedagógica posta. Sua motivação geralmente é humanizadora: "é necessário outro caminho", concebendo a situação de forma transitória: "o caminho não é assim - está assim".

Estudante intelectual crítico: percebe os procedimentos com animais como um problema, mas não o encara como situação-limite. Seu conceito de justiça é amplo, no entanto não se engaja: temerário da práxis por diversos motivos, acaba isolando-se do campo do protagonismo, seja por conveniência, comodismo ou por um ceticismo-imobilista. Sua motivação geralmente é desengajada: "(bem que) poderia ser por outro caminho".

Estudante intelectual adaptado: é ingênuo perante tais práticas, por não ser suficientemente crítico em relação a ela (não localiza a situação concreta de opressão). Ou não tem interesse por outras dimensões do conhecimento que fujam da esfera imediada e imediata, ou acredita que seus valores the preserva de qualquer engajamento possível. Pode possuir um senso de justiça restrito. Sua motivação geralmente é descompromissada: "não me interesso por outro caminho"; fatalista: "não há outro caminho"; ou marcada pelo silêncio.

Estudante intelectual hegemônico: acredita que tais práticas sejam necessárias em sua formação, legitimando seu valor didático-científico. Possui um senso de justiça restrito. Afinamse, neste aspecto, com os professores da mesma categoria, assumindo seu discurso. Sua motivação é afirmativamente opressora: "este é o caminho".

\section{Considerações finais.}

A mitificação da realidade acadêmico-científica (através de distorções do que seja o empreendimento científico e que aqui não será o caso de explorar) contribui para esta situação de imobilismo e do que Freire (1979) chama de falsificação da consciência: "seria impossível falsificar a realidade, como realidade da consciência, sem falsificar a consciência da realidade. Uma não existe sem a outra". A consequência deste processo é o prejuízo ao exercício da criticidade, que acaba por propalar as "excelências" da ordem vigente, e sua sacralização.

${ }^{1}$ Freire, P. Ação cultural para a liberdade e outros escritos. 4a edição. Rio de Janeiro: Paz e Terra, 1979. p. $96-97$ 
"Neste sentido, a escola, não importa qual seja o seu nível, vem desempenhando um papel dos mais importantes, como eficiente instrumento de controle social. Não são raros os educadores para quem 'educar é adaptar o educando ao seu meio' e a escola, em regra, vem fazendo outra coisa senão isso" $^{11}$

Segundo Paulo Freire, o professor também se diviniza nesta ordem vigente. A figura mitificada do professor, em sua autoridade, o torna intocável. Na educação científica de nível superior, a divinização é potencializada pelo status atribuído não apenas ao professor universitário, como também à sua afiliação científica. Questionar um renomado professor de fisiologia humana que trabalha como pesquisador há 30 anos, por exemplo, exige praticamente um espírito herege por parte de um estudante.

A postura que fataliza esta realidade, considerando-a como fato dado, marca o analfabeto político, segundo Paulo Freire. O cientista analfabeto político (e seu aprendiz) é aquele que foge da realidade concreta ao localizar-se no discurso da neutralidade da atividade científica, "indiferente ao uso que se faça dos seus achados (...). Quase sempre, ao ser indagado sobre isto, responde vagamente que está a serviço dos interesses da humanidade" (ibid). Assim, perde-se em visões abstratas do mundo.

\section{Concluindo...}

Considerando o campo de aplicação do pensamento de Paulo Freire, afirmado como aberto a novas experimentações, e devido a sua relevância no tema da docência, a experimentação didática em animais pode ser tratada, de forma crítica e contundente, a partir do referencial da pedagogia libertadora. A dimensão histórica, associada aos aspectos da intersubjetividade, dialogicidade e humanização, contempladas na obra deste educador, se configura como um rico instrumento que possibilita não apenas análises propriamente pedagógicas, como também epistemológicas e axiológicas. Sob este olhar, o uso de animais, enquanto experimento (instrumento) e experiência (vivência) didática consolidada, cada vez mais se caracteriza como um recurso e uma situação promotora da desumanização e da alienação, reforçando posturas hegemônicas em benefício da manutenção de concepções altamente questionáveis da práxis e da educação científica. Sua manifestação enquanto experimento pode ser compreendida enquanto sintoma de tal concepção, e utilizada como caricatura de uma prática contraditoriamente contemporânea, e repensada enquanto experiência, pela sua condição arbitrária e opressiva caracterizada pela não-dialogicidade.

1 Ibid. p. 101

R. B. E. C. T., vol 4, núm 2, mai./ago. $2011 \quad$ ISSN - 1982-873X 


\section{Referências}

Barbudo, C.R. O uso prejudicial de animais como recurso didático. Monografia de licenciatura em Ciências Biológicas - Universidade Federal de Alfenas (UNIFAL-MG), 2006.

Capaldo, T. The Psychological Effects on Students of Using Animals in Ways that They See as Ethically, Morally or Religiously Wrong. Alternative to Laboratory Animals, 32(1), pp.525-531, 2004.

Cyrino, E.G. e Toralles-Pereira, M.L. Trabalhando com estratégias de ensino-aprendizado por descoberta na área da saúde: a problematização e a aprendizagem baseada em problemas.

Cadernos de Saúde Pública, 20(3), pp. 780-788, 2004.

Brügger, P. Educação ou adestramento ambiental. 3a edição. Florianópolis: Letras Contemporâneas, 2004.

Delizoikov, D. La educación em ciências y la perspectiva de Paulo Freire. Revista Alexandria, 1(2). pp.37-62, 2008.

Freire, P. Pedagogia do oprimido. 47a edição. Rio de Janeiro: Paz e Terra, 2005.

Ação cultural para a liberdade e outros escritos. 4ạ edição. Rio de Janeiro: Paz e Terra, 1979.

Extensão ou comunicação? 8a edição. Rio de Janeiro: Paz e Terra, 1983.

Conscientização: teoria e prática da libertação: uma introdução ao pensamento de Paulo Freire. 3a edição. São Paulo: Editora Moraes, 1980.

Giroux, H. Escola crítica e política cultural. 3a edição. São Paulo: Cortez, 1992.

Lima, J.E.R. Vozes do Silêncio - Cultura Científica: ideologia e alienação no discurso sobre vivissecção. São Paulo: Instituto Nina Rosa, 2008.

Mejía, M.R. Paulo Freire na mudança de século: um chamamento para reconstruir a práxis impugnadora. In: Streck, D.R. et al. (Orgs.). Paulo Freire: ética, utopia e educação. 5ạ edição. Petrópolis: Editora Vozes, 1999.

Mendonça, N.J.A. A humanização na pedagogia de Paulo Freire. Dissertação. UFPE, 2006.

Mirault-Pinto, M.C.M. e Rímoli, A.O. Vivência dos estudantes das áreas biológicas, agrárias e da saúde da Universidade Católica Dom Bosco quanto ao uso de animais em aulas práticas. Revista Biotemas, 18(1), pp. 193-215, 2005. 
Mirault-Pinto, M.C. Objeção consciente ao uso de animais: o conflito na sala de aula. In: Trez, T.A. (Org.) Instrumento animal: o uso prejudicial de animais no ensino superior. Bauru: Canal 6 , 2008.

Rozendo, C.A.; Casagrande, L.D.R.; Schneider, J.C.; Pardini, L.C. Uma análise das práticas docentes de professores universitários da área da saúde. Revista Latino-Americana de Enfermagem. 7(2), pp.15-23, 1999.

Scocuglia, A.C. A história das idéias de Paulo Freire e a atual crise de paradigmas. 2a edição. João Pessoa: Ed. Universitária UFPB, 1999a.

A construção da história das idéias de Paulo Freire. In: Streck, D.R. et al. (Orgs.).

Paulo Freire: ética, utopia e educação. 5a edição. Petrópolis: Editora Vozes, 1999b

Shiue, H.M.; Alves, L.C.; Cavalcante-Silva, F.A.; Fonseca-Cavalcanti, M.; Felinto, C.P.; Vasconcelos, S. Utilização de animais para fins didáticos: percepção de alunos e docentes da Universidade Federal de Pernambuco. In: XV Congresso Brasileiro de Zoologia, Brasília - DF. XV Congresso Brasileiro de Zoologia, 2004. p.453

Sousa, A.S. Uso de animais para fins didáticos: percepção dos estudantes e professores dos cursos da área de saúde da FTC - Salvador. Monografia de bacharelado - Faculdade de Tecnologia e Ciências, Salvador, 2007.

Tréz, T. O Uso de Animais Vertebrados como Recurso Didático na UFSC: Panoramas, Alternativas e a Educação Ética. Trabalho de Conclusão de Curso - Universidade Federal de Santa Catarina, Santa Catarina, 2000.

. O ensino anti-sensorial: os valores da vivissecção na educação científica. In:

Guimarães, L.B.; Brugger, P.; Souza, S.C.; Arruda, V.L.V. (Orgs.). Tecendo subjetividades em educação e meio ambiente. Florianópolis: NUP/CED/UFSC, 2003.

Tréz, T.A. E Nakada, J.B. Percepções acerca da experimentação animal como um indicador do paradigma antropocêntrico-especista entre professores e estudantes de Ciências Biológicas da UNIFAL-MG. Revista Alexandria, 1(3), pp. 3-28, 2008.

Vara Federal Ambiental. Ação Ordinária (Procedimento Comum Ordinário) № 2007.71.00.019882-

0/RS, 2008. Disponível em: http://www.trf4.jus.br (acesso em 6 de maio de 2010) 
Thales de Astrogildo e Tréz. Docente do Instituto de Ciências Humanas e Letras, Universidade Federal de Alfenas (Unifal-MG). Mestre em Ética Aplicada pela Universidade Católica de Leuven (Bélgica). Doutorando do Programa de Pós-Graduação em Educação Científica e Tecnológica, Universidade Federal de Santa Catarina. thales.trez@unifal-mg.edu.br 